\title{
Principio de precaución y agravios comparativos en la gestión de la arqueología y la paleontología por parte de las administraciones: el caso de la Comunidad Valenciana
}

Francisco Javier Ruiz Sánchez | Área de Paleontología, Universitat de València

URL de la contribución <www.iaph.es/revistaph/index.php/revistaph/article/view/4177>

El Diccionario de la Real Academia Española define "agravio comparativo" como "trato desigual a personas que tienen o creen tener el mismo derecho a algo en determinada situación". Otros diccionarios amplían el significado de este término a cosas y no solo a personas, y así el Spanish living Oxford Dictionaries (Oxford University Press) lo define como "daño u ofensa que se hace a una persona o cosa al tratarla de modo diferente que a otra de su misma condición o en una misma situación". Conocer tanto la acción (trato desigual-trato de modo diferente), como las circunstancias del sujeto (en este caso, paleontología y arqueología) que recibe la acción son importantes de cara a conocer la realidad de la gestión de estos valores en el territorio.

Nuestro Estado de las autonomías establece un marco legislativo y competencial en el que cada autonomía ejerce sus competencias dentro de un sistema basado en lo que marca su Estatuto de Autonomía y la legislación básica que emana del Estado, UE, convenios, etc. (Aparicio, 1981 in Ruiz-Sánchez, 2005). La gestión de una materia particular (arqueología o paleontología) puede variar mucho dependiendo del marco legislativo del que se ha provisto la autonomía.

En referencia a la paleontología, en el Estado español esta materia tiene dos aproximaciones legislativas diferentes: se encuentra regulada parcialmente por normas de patrimonio cultural (Ley 16/1985, de 25 de junio) y también del patrimonio natural (Ley 42/2007, de 13 de diciembre). En este contexto, cada comunidad autónoma, en el marco de sus competencias, han regulado la materia y su ejecución (gestión) (MELÉNDEZ; SORIA, 1999).
La legislación de impacto ambiental es una de las bases sobre las que se fundamenta la protección de los recursos naturales y culturales (RUIZ-SÁNCHEZ, 2005). Cuando la arqueología y la paleontología se gestionan conjuntamente se observan diferencias poco justificables. En este trabajo se describe, muy someramente, la dispar forma cómo son tratadas ambas materias a la hora de identificar y valorar los impactos en los procedimientos de evaluación del impacto ambiental en la Comunidad Valenciana. Es necesario considerar no solo la protección pasiva y/o activa que suponen las figuras de protección en el marco de los espacios naturales protegidos, sino también la gestión que posibilitan los procedimientos de evaluación del impacto ambiental de las actuaciones humanas sobre el medio natural (RUIZSÁNCHEZ, 2005).

\section{El caso concreto de la Comunidad Valenciana}

En los más de $23.000 \mathrm{~km}^{2}$ de superficie que abarca la Comunidad Valenciana, son las rocas sedimentarias las que mayor porcentaje del territorio ocupan (SANTANACH; BANDA; CALVET, et ál., 1986; SANCHÍS MOLL; RODRÍGUEZ ESTRELLA; MORELL EVANGELISTA, 1988; GUIMERÀ; ANADÓN; CABRERA, et ál., 1992), existiendo una media-alta probabilidad de encontrar restos fósiles a partir de una actuación con remoción del terreno. De igual manera, el territorio de lo que hoy en día conforma la Comunidad Valenciana ha sido encrucijada de caminos de un buen número de culturas, que han propiciado un rico y variado legado cultural. Por tanto, y tal como queda expresado en la Ley 11/1994, de Espacios Naturales protegidos de la Comunidad Valenciana y la Ley 4/1998, de Patrimonio Cultural Valenciano, consti- 
a debate El marco legal para la protección del patrimonio paleontológico. ¿Qué pasa en tu comunidad?

tuyen algunas de ".. las principales señas de identidad del pueblo valenciano y el testimonio de su contribución a la cultura universal... siendo un legado patrimonial de inapreciable valor, cuya conservación y enriquecimiento corresponde a todos los valencianos e instituciones y poderes públicos que los representan".
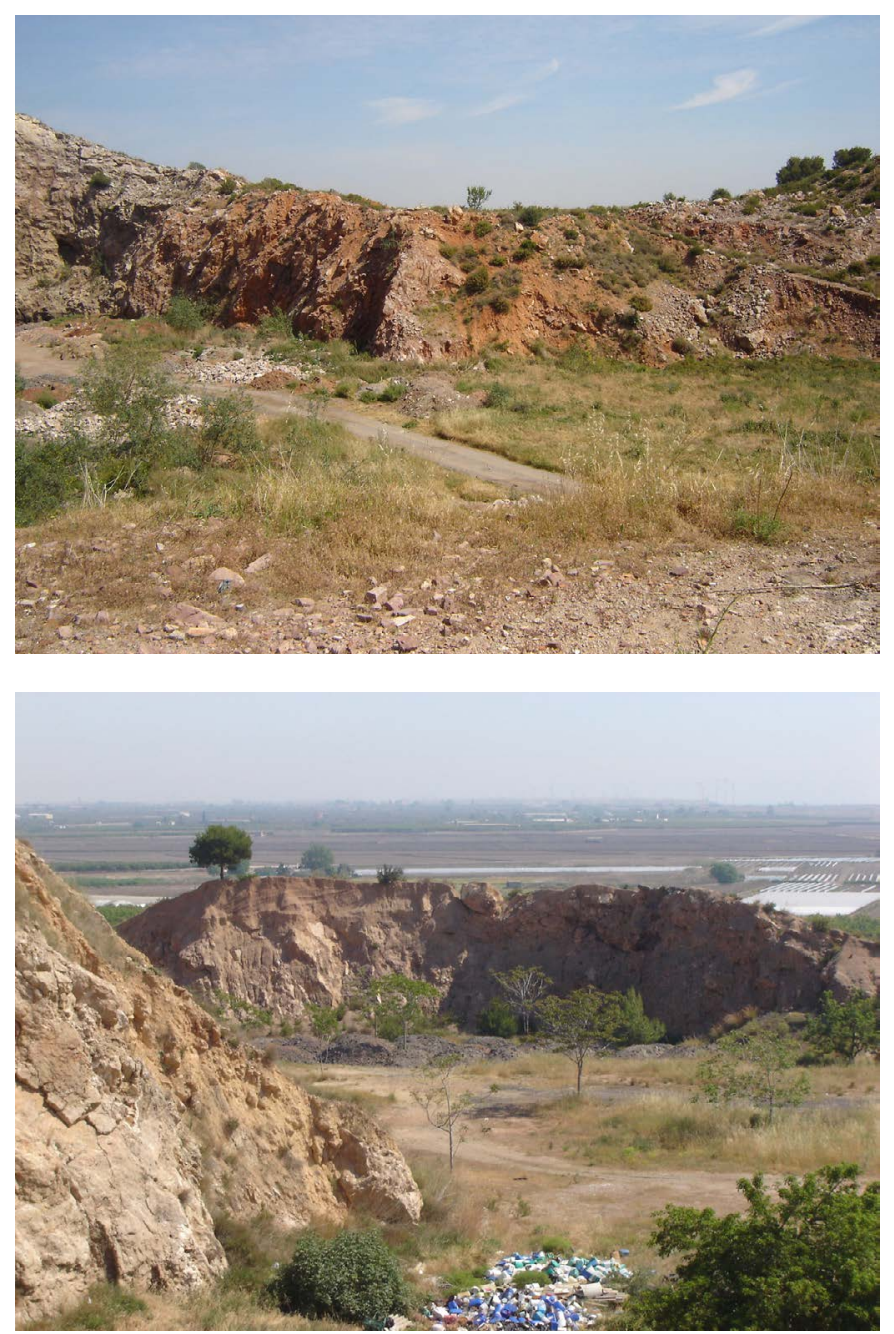

Vertedero de residuos controlados de la localidad castellonense de Almenara. Al fondo se observan los terrenos de la Marjal d'Almenara correspondiente a los municipios de La Llosa y Chilches. En el interior del vertedero se puede observar el relleno cárstico, en su mayor parte cubierto por toneladas de residuos sólidos urbanos, en cuya parte inferior se localiza el yacimiento Almenara Casablanca 3 (ACB-3). La falta de un riguroso estudio de impacto ambiental en el momento de construcción del vertedero ha llevado a la destrucción de ACB-3 | fotos Francisco Javier Ruiz Sánchez
La Orden de 3 de enero de 2005, de la Generalitat Valenciana, por la que se establece el contenido mínimo de los estudios de impacto ambiental regula que estos estudios identificarán y valorarán los impactos, tanto en la solución propuesta como sus alternativas, incorporando (entre otros documentos) el informe vinculante de conformidad del proyecto con la normativa de protección del patrimonio cultural que se recoge en el art. 11 de la Ley 4/1998 de Patrimonio Cultural Valenciano (Memoria de Impacto Patrimonial, según el Decreto 208/2010). Este informe vinculará a la administración que debe realizar la declaración de impacto ambiental. El Decreto 208/2010 de la Generalitat Valenciana establece el contenido mínimo de las memorias de impacto patrimonial que pudieran afectar a los bienes integrantes del patrimonio histórico, artístico, arqueológico y paleontológico en el caso de los planes y programas sujetos a evaluación ambiental estratégica o de proyectos sujetos a estudio de impacto ambiental. Según este Decreto, para valorar la posible incidencia del proyecto, plan o programa, obra o actividad respecto al patrimonio arqueológico será preceptivo llevar a cabo una prospección arqueológica, que deberá contemplar la totalidad del ámbito de afección del proyecto evaluado, incluyendo todas las obras auxiliares asociadas, y deberá incluir la prospección de un entorno mínimo de 50 metros desde el límite de afección (ampliable a 2000 metros en las actuaciones lineales). Por el contrario, y según este Decreto, para el patrimonio paleontológico, el promotor deberá consultar previamente las cartografías que delimitan las áreas de bajo potencial paleontológico de la Comunidad Valenciana, y si el proyecto se ubica íntegramente en estas áreas solo se deberá incluir justificación documentada de esta circunstancia en el estudio de impacto ambiental.

Según la descripción que hacíamos del "agravio comparativo", tanto los valores arqueológicos y paleontológicos tienen una misma condición (recursos protegibles) y una misma situación (capaces de ser destruidos en caso de actuación humana incontrolada). Ante esta situación solo nos podemos hacer preguntas que no por insidiosas dejan de tener sentido. ¿Por qué entonces se gestionan de forma tan diferente? ¿Son acaso 
a debate El marco legal para la protección del patrimonio paleontológico. ¿Qué pasa en tu comunidad?

tan exhaustivas las cartografías de esas áreas de bajo potencial paleontológico de la Comunidad Valenciana como para intentar evitar uno de los principios básicos de la evaluación ambiental, y que no es otro que el principio de precaución?

El principio de precaución se menciona en el artículo 191 del Tratado de Funcionamiento de la Unión Europea, y lo que pretende es garantizar un elevado nivel de protección del medio ambiente mediante tomas de decisión preventivas en caso de riesgo. El recurso a este principio se inscribe, por tanto, en el marco general del análisis de riesgo y, más concretamente, en el marco de la gestión del riesgo que corresponde a la fase de toma de decisiones (Comunicación EU-[COM(2000) 1 final] sobre el recurso al principio de precaución).

Parece obvia la respuesta a alguna de las preguntas formuladas (al menos a la pregunta sobre la exhaustividad de estas cartografías sobre el bajo potencial paleontológico), cuando puede comprobarse que estas áreas representan casi en su totalidad los depósitos cuaternarios en la Comunidad Valenciana. ¿Es la posible presencia de restos humanos en esos depósitos, y por tanto su adscripción a "lo arqueológico" (según alguna línea de pensamiento en el ámbito de la arqueología) la razón de este proceder por parte de la administración?

\section{BIBLIOGRAFÍA}

- APARICIO, M. A. (1981) Introducción al sistema político y constitucional español. Barcelona: Ariel, 1981

- COMUNICACIÓN EU-[COM(2000) 1 final] sobre el recurso al principio de precaución [en línea] <https://eur-lex.europa.eu/ legal-content/ES/TXT/?uri=LEGISSUM\%3AI32042> [Consulta: 15/04/2018]

- GUIMERÀ, J.; ANADÓN, P.; CABRERA, L.; ESTÉVEZ, A.; MARTÍ, J.; TABERNER, C. (1992) Geologia II. En Enciclopèdia d'Història Natural dels Països Catalans. Barcelona: Enciclo pèdia Catalana S. A., 1992, pp. 1-548

- LEY 16/1985, de 25 de junio, del Patrimonio Histórico Español. Boletín Oficial del Estado, n. ${ }^{\circ}$ 155, de 29 de junio de 1985
- LEY 42/2007, de 13 de diciembre, del Patrimonio Natural y de la Biodiversidad. Boletín Oficial del Estado, n. ${ }^{\circ} 299$, de 14 de diciembre de 2007

- MELÉNDEZ, G.; SORIA, M. (1999) Situación Actual del Patrimonio Paleontológico en España. PH: Boletín del Instituto Andaluz de Patrimonio Histórico, n. ${ }^{\circ} 29,1999$, pp. 128- 141

- RUIZ-SÁNCHEZ, F. J. (2005) La legislación de medio ambiente y la protección del patrimonio paleontológico en la Comunidad Valenciana (España). Revista Española de Paleontología, vol. 10, 2005, pp. 119-124

- SANCHÍS MOLL, E. J.; RODRÍGUEZ ESTRELLA, T.; MORELL EVANGELISTA, I. (1988) Geología. En SANCHÍS MOLL E. J. (dir.) Guía de la naturaleza de la Comunidad Valenciana. Valencia: Ediciones Alfonso el Magnánimo, 1988, pp. 19-72

- SANTANACH, P.; BANDA, E.; CALVET, F.; CARRERAS, J.; CASAS, J. M.; FONTBOTÉ, J. M.; FORNÓS, J.; GISBERT, J.; JULIVERT, M.; MARZO, M.; RODRÍGUEZ-PEREA, A.; SALAS, R.; BOUQUET, P. (1986) Geologia I. En Enciclopèdia d'Història Natural dels Països Catalans. Barcelona: Enciclopèdia Catalana S. A., 1986, pp. 1-439 